\title{
Pedagogy of the Devil
}

\author{
Hamza Cherifi \\ Department of Foreign Languages, Khemus Miliana University, Algeria \\ Temmamra City; El amra,44010, Ain Defla Province, Algeria
}

The research is financed by Asian Development Bank. No. 2006-A171(Sponsoring information)

\section{Abstract}

I postulate that temptations of dehumanization get efficiently exercised by means of education. It is school, more than anything else, that is likely to perfect the art of distorting humanity with absolute sense given likelihood of fallacies on the functions and potential of mind - the entity setting mankind apart. The fallacy lies in rendering the free-thinking, creative mind artificial and mechanistic, by establishing strict correlations between intellectual traits and disciplinary or scholastic constrains, and by fixing the tangible flow of thoughts as connected with the living and spontaneous course of entities and incidents. The outcome of such practice is a constantly centralized prototype of a detached and reasoning shaped by prejudice, and it is deeply resilient to change in the minds of individuals.

Keywords: pedagogy of the devil; education; learners; thinking

DOI: $10.7176 / \mathrm{JEP} / 11-29-09$

Publication date:October $31^{\text {st }} 2020$

\section{Introduction}

A salient feature of education is that it is determinant and all-embracing. This centrality features in all domains being bound up with and informed by education, and in schools being an imparter of conception and the director of thinking, reflection and judgments: No domain implicates and governs thinking as education. This latter industry marks the backbone, and a high-standard education has throughout history characterized the greatest of nations. The fact, however, remains that no matter how effective education might be, the free-thinking mind is still in threat for learners' reasoning becomes more and more detached from reality:

A common view is that as a student progresses from year to year in school, the academic orientation to teaching and learning becomes more dominant. It overrides play and personal exploration that characterize early years of schooling. Indeed, schools do have a great potential to enhance human ecology by removing barriers and utilizing the potential for more creative learning environments (Sahalberg, 2009, p. 337).

A good education does at best minimize artificial reasoning. Hence, outcomes of bad schooling must be disastrous and do warrant elaboration. In what follows, I elaborate of a concept I call Pedagogy of the Devil: I will be revealing how humanistic thinking gets skewed by education as way to raise awareness over what kind of threat education per se might bring to mankind, and how institutions, while said to promote man's wellbeing, relegate individuals to the utmost state of absurdity and fragile, escapist consciousness.

\section{Restricting the Mind}

Pedagogy of the Devil — whether deliberately or not - undertakes a mind restriction process, namely by associating potentialities or skills with scores, objectives or degrees. Not only might these measures be unreliable, what is more startling is that they are allotted the property of signposts for what and how to reason. The naturalist reasoning learners bring with turns sluggish and mechanistic. The prestige value we assume of matters of 'methods', 'approaches' and 'programs' leads us to think of reasoning in terms of attained objectives. This goes along with deep conceptions of success beliefs that run counter to creativity and the ability to ponder real issues. Learners get also confined by the authority of profession than that of knowledge and critique.

The teacher's personality and degree of acceptance largely dictates what learners think as suitable to take from the large conceptual repertoire build by the environment, meaning that the less open the teacher is, the less daring are the students to oppose or propose. It is this rigid, inflexible, and intangible learning environment that prevents learners from bringing to class the same thinking they operate outside. What is more startling is that the natural experiences learners might be denied mark the incentive for creative spirit (Wiliams \& Johnson, 2018). Instead, meeting the teacher's expectation becomes a striven-for aim, all at the cost of self-expression and the enjoyment found in the tangible, limitless reasoning originating in natural sequence of things. A teacher's hegemony causes learners to conceive their anecdotes and experiences as irrelevant, leading to loss of selfconfidence and undermining of oneself, and, by extension, of one's local cultural capital. As such, learners get mentally persecuted and denied of significance, with the feeling of self-deception hanging on their minds. They get often scared of not scoring well in case they demonstrate output unfamiliar to the teacher. It is learners tending to know at the span of their teachers, and it is under the purview of this one-sided entity that naturalistic reasoning and the whole set of learners' background knowledge get submerged. By the standards of Pedagogy of the Devil, learners are informed of what they think themselves able to do, and it is teachers who think for learners. 


\section{A Mythical Reality}

Pedagogy of the Devil drags to a mythical form of reality through two main manners: Muffling the specificities of individuals and centralizing mere understanding and theory. A corresponding education must be communityspecific (Ferire, 1962/1972) : The conceptual and baseline underlying its design, objectives, and implementation comes from the context with all the totality of cultural, cognitive, ethical, and historical parts, along with the society's true issues and expectations. A pedagogy specific to one community not only goes irrelevant, it poses a foreignizing threat that alienates individuals and drag them away from real brushes. In this sense, learners handle and scrutinize issues which are not theirs, and school offers not the desired continuity and refuge. The practice of adapting others' pedagogy makes learners feel alien and awkward, especially when this very kind of school is idealized. In alignment with this, Pedagogy of the Devil minimizes research purporting to investigate the properties of learners, including their characteristics, folklores, prior knowledge, mother tongue and preferences, which are all needed for boosting motivation and establishing continuity between school and society.

The other way of fabricating a mythical reality is packing learners with theories about the nature of things. This practice sparks confusion and uncertainty, where learners find it hard to build on firm ideational basis. With the flow of theories and accounts at the cost of triggering practice and involvement, not only learners find difficulties disentangling judgments and ideas about moves and incidents, but they also build an impression of incapacity to form or reach conclusions. Research, here, merely seeks to show understanding of particular phenomenon and allocating it certain attributes.

A school functioning this way is often stereotyped and lamented by the layman, who often complains that education does not prepare for life. For the layman, education does not simulate true challenges and true tales of life, and hence distorts living. Victims of this pedagogy must lack motivation which essentially relates to social and incidental saliencies characterizing one's usual. Pedagogy of the Devil yields people incapable of catering for contextual issues. It devises a lazy population perceiving no problem to solve and no bad situation to better. Education, instead of creating a society of actions, can prompt one of illusion and subjugations.

\section{Dampening Self-esteem}

Essential for independent thinking is the feeling of worth and self-confidence which makes up higher self-esteem (Barbot 2018; Karwowski, 2016; Barbot \& Heuser, 2016). Conversely, it is the conviction of inability and inferiority that Pedagogy of the Devil instills. Under this pedagogy learners position as lacking individuals destined to be deposited. They get constantly drawn to believe that accurate thinking locates everywhere except inside themselves. Learners' perception of scholars and referenced depositors of knowledge as supernaturally qualified beings leads them to conceive a huge distance, thereby to undermine their potentials which are indirectly dictated. It is even that suggestions and simplistic probing of the nature of things are regarded non-debatable facts.

This leads to the suspension of doubt, which is the basis of evaluative thinking. The reason why learners do not dare to suggest or critique is that they have not been led to see themselves able to do so, and that a position of this kind is quite self-relegating. This psychological inferiority results from the anti-dialogical legacy, the oneway communication style, and the assertive, narrative tone.

Learners, whose role we suppose to be theorizing and resorting to education to solve real-life problems, are made mere readers. How much they read and how much knowledge they have marks a fundamental measure of their intellectualism. The more you read the better learner you are. Despite its benefits, the reading method might turn out to become a means for depositing knowledge and indoctrination.

The practice of idealizing the pre-planned dampens one's enthusiasm, where reasoning is found useless before the planned and methodic stuff. The notion of methodism gives the impression that everything has been thought of so carefully, especially when the stuff presented as 'theory-based' or 'pedagogic' belongs to non-local people, with whom regulated learners must be obsessed.

One serious display of Pedagogy of the Devil is creativity mistaken for activism. Learners are often thought of brilliant by being active, reproducing teachers' insights and "being at their expectations". In effect, pleasing the teacher is almost everything learners seek to achieve. Similarly, silence is mistaken for passivism, while praise is to those who "say something", for a mere reason that they take the turn from the teacher "who should not", of course, "do everything".

\section{Unreliability and Violent Expectations}

Assessment policies are also accountable for the construction of our scene. The status of assessment gets reduced from informing of learners' state in relation to given material to the mere purpose of filling evaluation sheets to satisfy administrative needs. This conclusion is attained through observing different intersecting factors, main of which is test items. It follows from this that degrees based on the pass mark worth almost nothing at the intellectual level. What degrees seem to stand for most is the ability to adhere to administrative requirements. More absurdity is assumed over whether measures of deciding success or failure are accurate, casting doubt on the test validity and reliability (See Carr, 2011). 
This pedagogy goes very much resentful to individuals with tangible, realistic minds, persons with creativity, with a natural state of mind (Karwowski, 2016; Barbot \& Heuser 2017; Barbot, 2018). The militant learners who show resilience would surely suffer marginalization. The 'rebels, the 'trouble makers', 'the intellectually odd' who could not afford to get absurd for pride forces, would face rejection and charges for disloyalty to the regime.

In a more general living standard, Mikhail Bakhtin (1981) refutes such monologist, one sided "accentuation", highlighting its repressive repercussions in a much more overriding ideological and political. Does a teacherlearner relation reflect social oppression? Is education the main server of dominance and hegemony? Borrowing Bakhtin's words, just like the oppressor, the teacher ignores other "competing voices" and "strive to fix meaning. In so doing, those tending to show slight backing from the regime are held "voiceless slaves". And since the voices of learners reflect a difference sourced in a different living social ideology, a teacher allows for a distortion of reality whose true reflection is this very difference. Hence, a teacher's monologic practice does subordinate the naturalness of other voices under an intangible hegemony proclaiming self-sufficiency. It is also in this sense that education cripples indigenous stories of thinking and life.

The deadly social repercussions are twofold: First, other equally significant voices get assassinated, ideas and probing of the nature of things that typify life and diverse historicity that should be rather appreciated and considered as co-existing manners. What is more startling is that these muffled voices in education might offer alternatives and solutions corresponding to the naturalness of the rising barriers in communities and worldwide. Second, subverted individuals would grow a consciousness of passivism and uselessness strikingly resilient to change. In bringing the case of Albert Einstein, a prototype of a living, "non-conformist" voice with different, alternative ideas suffering alienation from forces of educational fixity, Kincheloe et al. (1999) give the following wordings:

Modern education wisdom speaks of fitting school into the student in a way that accommodates the education of students in all sectors of the educational sectors. A paradox exists, however, when hidden structures of the school are exposed, structures that emphasize epistemologies that define learning as "mastery" of isolated bits of knowledge, marginalize conceptual knowledge, define divisions among students in terms of ability levels, and fail to understand...indigenous people way of knowing, and other subjugated knowledges (p. 27).

Whoever dares operate outside the agenda is likely to 'fail', for the measure is everything but what they genuinely desire to demonstrate as this does not bear 'pedagogical justification'. On the other hand, attendance, reproduction, paraphrasing, subjection to curricular and institutional guidelines appear to constitute a set of 'competencies'.

\section{Conclusion}

Education can perfectly robotize and deny of the human saliencies, notably through the meddling in the naturalness of reasoning. The fact, however, remains that policies and managerial decisions make not the sole actorssometimes they are just peripheral. Pedagogy of the Devil seems equally constructed by thriving envy rather than contextual and disciplinary constraints. It is a manner of thinking motivated by lack of awareness, responsibility, and dignity. Yet an indirectly related issue, we need to be really aware of, is the evil of man; the tendency of some teachers not affording to benefit learners in the real sense, by concealing what they know as important and efficient, and their enviously fearing to be "surpassed" by students of theirs.

\section{References}

Barbot, B. (2018). Creativity and self-esteem in adolescence: a study of their domain-specific, multivariate relationships, The Journal of Creative Behavior, 0, Iss, 1-14.

Bakhtin, M. The dialogic imagination: four essays.(C. Emerson, Trans., M Holquist, Ed.). Austin, TX: University of Texas Press.

Barbot, B., \& Heuser, B. (2017). Creativity and personal identity in adolescence: a developmental perspective. In M. Karwowski \& J.C. Kaufman (Eds.), The Creative Self: Effects of Beliefs, Self-efficacy, Mindset and Identity, 87-98. London: Academic Press.

Carr, N. (2011). Designing and analyzing language tests. Oxford: Oxford University Press.

Ferire, P. (1972). Pedagogy of the oppressed. New York: Herder and Herder.

Karwowski, M.(2016). The dynamics of creative self-concept: changes and reciprocal relations between creative self-efficacy and creative personal identity, 28, Creativity Research Journal, 99-104.

Kincheloe, J., Steinberg, S., \& Tippins, D. (1999). Einstein the student, Einstein the teacher. The Stigma of Genius: Einstein, Consciousness, Education, 111, 27-47.

Sahalberg, P (2009). The role of creativity in promoting creativity: potential barriers and enabling factors. In E. Vilalba (Ed.), Measuring Creativity, 337-344 Luxemburg: OPOCE.

Wiliams, K., \& Johnson, K.(2018). Conceptualizing creativity benefits of nature experience: attention restoration and mind wandering as complementary processes, Journal of Environmental Psychology 18, 36-45. 